\title{
Inhibition of pathophysiological proteases with novel quercetin derivatives
}

\author{
Martina Danihelováa , Miroslav Veverka ${ }^{\mathrm{b}}$, Ernest Šturdik ${ }^{\mathrm{a}}$ \\ ${ }^{a}$ Institute of Biochemistry, Nutrition and Health Protection, Faculty of Chemical and Food Technology, \\ Slovak University of Technology, 81237 Bratislava, Slovakia \\ ${ }^{b}$ Bel/Novamann International s.r.o., 81571 Bratislava, Slovakia \\ martina.danihelova@stuba.sk
}

\begin{abstract}
Novel quercetin derivatives were prepared to change its physicochemical properties and effects on activity of proteolytic enzymes. For them preparation, the selective protection procedures some of the quercetin hydroxyl groups and acylation of the others with acylchlorides were used. The ability of these compounds to inhibit the activity of serine proteases e.g. trypsin, thrombin, urokinase and elastase was studied. In micromolar range, tested derivatives were the most potent inhibitors of thrombin. There was estimated better inhibition of thrombin for prenylated, acetylated, feruloyl and caffeoyl quercetin esters. Slight inhibitory effect of all quercetin derivatives on elastase was found. Among tested derivatives only diquercetin displayed better inhibiton. Trypsin and urokinase were inhibited by quercetin at comparable level. Slight improvement in inhibitory effect of trypsin and urokinase was seen for chloronaphtoquinone quercetin that revealed enhanced inhibiton of thrombin, too. However, no influence on elastase activity was determined for this compound. Obtained results indicate that certain modifications of quercetin structure could improve its biological properties.
\end{abstract}

Keywords: elastase, enzyme inhibition, quercetin derivatives, thrombin, trypsin, urokinase

\section{Introduction}

Serine proteases belong to the most studied class of proteolytic enzymes. They are a primary target in the drug development field (Muri et al., 2005). Interest in this family of enzymes is due to their diverse role in a host of physiological and pathological processes. Serine proteases include digestive enzymes, enzymes participating in blood coagulation, inflammation and numerous other processes (Walker and Lynas, 2001).

Action of elastase, one of the serine proteases, implicates in pathogenic agent killing and in inflammatory process regulation (Korkmaz et al., 2010). The other one, thrombin, is considered the central enzyme of the coagulation cascade. Abnormal thrombin generation can be seen not only in cardiovascular disorders, but also in inflammation or immune diseases (Petros and Siegemund, 2011). Overactivity of urokinase is a causal determinant to tumor metastasis (Carriero et al., 2011). Trypsin has an important role in digestion. But excessive action leads to inflammatory conditions and tumor progression (Yamamoto et al., 2003; Keisuke et al., 2005). Protease inhibitors thus have considerable potential utility for therapeutic intervention in a variety of disease states.

Majority of the plant derived protease inhibitors are proteins in nature and they directly bind to the active site of serine proteases through competitive inhibition (Shahwar et al., 2012). Many publications document that flavonoids, a class of natural polyphenolic substances, also possess inhibitory ef- fect on various enzymes including serine proteases. They are effective in inhibition of serine proteases like trypsin (Parellada and Guinea, 1995; Maliar et al., 2004; Jedinák et al., 2006; Shahwar et al., 2012), thrombin (Jedinák et al., 2006; Mozzicafreddo et al., 2006; Liu et al., 2010), urokinase (Devipriya et al., 2006; Jedinák et al., 2006) or elastase (Kanashiro et al., 2007; Krenn et al., 2009; Philips et al., 2010).

Among tested flavonoids quercetin exhibited the best inhibitory action on trypsin, thrombin and elastase (Maliar et al., 2004; Mozzicafreddo et al., 2006; Kanashiro et al., 2007). However, its bioavailability is not sufficient (Viskupičová et al., 2008). Some papers are describing enhancement of enzyme inhibition upon quercetin structure modification (Chen et al., 2001; Kartasasmita et al., 2010; Takahama et al., 2011; Veverka et al., 2013). We therefore prepared a set of new synthesized quercetin derivatives to modify its polarity and inhibitory properties on proteolytic enzymes, too. These derivatives were previously monitored for its antioxidant capacity (Kružlicová et al., 2012) and inhibition of aldose reductase (Veverka et al., 2013). In the present paper we evaluated them for their inhibitory effect to serine proteases trypsin, thrombin, urokinase and elastase.

\section{Materials and methods}

\author{
Materials \\ Trypsin from porcine pancreas (EC 3.4.21.4, \\ $2000 \mathrm{BAEE} \mathrm{U} / \mathrm{mg}$ ), thrombin from bovine plasma
}


(EC 3.4.21.5, $2000 \mathrm{NIH} \mathrm{U/mg),} \mathrm{elastase} \mathrm{from}$ porcine pancreas (EC 3.4.21.36, $4 \mathrm{U} / \mathrm{mg}$ ), N $\alpha$ benzoyl-D,L-arginine-p-nitroanilidehydrochloride, N-glycine-arginine-p-nitroanilide dihydrochloride, quercetin, No-benzoyl-L-phenylalanyl-L-valyl-Larginine-p-nitroanilide hydrochloride, N-succinylL-alanyl-L-alanyl-L-alanine-p-nitroanilide and 4-guanidinobenzoic acid hydrochloride were purchased from Sigma-Aldrich. Urokinase $500000 \mathrm{HS}$ from human urine (EC 3.4.21.73, $500000 \mathrm{IU} / \mathrm{mg}$ ) was from Medac GmbH. All solvents and other reagents were supplied from local companies and were of analytical or HPLC grade.

\section{Synthesis of quercetin derivatives}

The synthesis of different quercetin esters, bearing from mono- to tetra- substituted hydroxyl groups, was achieved in simple procedures whereas yields of isomers depend on the stoichiometric ratio of reagents. The strategy of direct acylation of quercetin with chloropivaloyl chloride gives complex reaction mixture. The crude reaction mixtures were analyzed (LC-MS) and compared with isolated products. Products were purified by column chromatography, crystallized, and characterized by elemental analysis, NMR, IR, EI mass spectroscopy. Unambiguous structural characterization of isomeric quercetin derivatives was confirmed by NMR analysis (Veverka et al., 2013).

\section{Analytical methods}

Products were purified by column chromatography, crystallized, and characterized by elemental analysis, NMR, IR, EI mass spectroscopy. Unambiguous structural characterization of isomeric quercetin derivatives was confirmed by NMR analysis (Veverka et al., 2013). For TLC analysis samples were placed on silica glass plates and eluted with dichloromethane/methanol/formic acid (9/0.5/0.1, $9 / 0.2 / 0.1$ or $9 / 0.1 / 0.1, \mathrm{v} / \mathrm{v} / \mathrm{v})$ and ethylacetate/ methanol $(9 / 0.1, \mathrm{v} / \mathrm{v})$. Quercetin derivatives were detected under UV light at $254 \mathrm{~nm}$.

\section{Assessment of enzyme inhibition}

To determine enzyme inhibition we used spectrophotometric method that was reported previously (Erlanger et al., 1961; Bieth et al., 1974; Vinazzer, 1975; Nieuwenhuizen et al., 1977). We adapted methodological modifications according Jedinák et al. (2006). Suitable chromogenic substrates were applied for particular enzymes, concrete N $\alpha$-benzoyl-D,L-arginine-p-nitroanilide hydrochloride for trypsin, N-glycine-argininep-nitroanilide dihydrochloride for urokinase, Na-benzoyl-L-phenylalanyl-L-valyl-L-argininep-nitroanilide hydrochloride for thrombin and
$\mathrm{N}$-succinyl-L-alanyl-L-alanyl-L-alanine-p-nitroanilide for elastase.

Hydrolysis of substrates released free nitroaniline, that was measured at $410 \mathrm{~nm}$ using microplate screening system on microplate photometer (Multiscan FC, Thermo Scientific, China). Hydrolytic reactions of substrates $(0,03 \mathrm{M})$ and trypsin (6 BAEE $\mathrm{U} / \mathrm{ml})$, urokinase $(25000 \mathrm{IU} / \mathrm{ml})$, thrombin $(0$, $116 \mathrm{NIH} \mathrm{U} / \mathrm{ml})$ and elastase $(0,012 \mathrm{U} / \mathrm{ml})$ were carried out in phosphate buffered saline $(0,01 \mathrm{M}$, $\mathrm{pH}=7,4)$ at $37^{\circ} \mathrm{C}$ during $60 \mathrm{~min}$.

All tested compounds were initially solubilized in dimethyl sulfoxide (DMSO) (giving $10 \mathrm{mM}$ stock solutions) and subsequently diluted in the reaction mixture to various final concentrations (in the range from 12.5 to $200 \mu \mathrm{M}$ ). The highest concentration of DMSO in the reaction mixture never exceeded $2 \%$. The absorbance was measured in the $1^{\text {st }}$ and $61^{\text {st }}$ minute after reaction started. Each experiment was performed in quintuplicate. Inhibitory effect was expressed as the concentration that is responsible for $50 \%$ of substrate cleavage inhibition $\left(\mathrm{IC}_{50}\right)$. $\mathrm{IC}_{50}$ values were stated from the relationship of compound concentration and its inhibitory effect. Data were presented as means of the percentage of control $\pm \mathrm{SD}$ (standard deviation).

\section{Results and discussion}

\section{Synthesis of quercetin derivatives}

As the initial molecule suitable for modification quercetin was chosen because of its proven health beneficial effects (Boots et al., 2008), low cost and common occurence among fruit, vegetable and medicinal plants (e.g. onion, apple, parsley, green tea, grapes, sage). We used the simple condensation reactions (Fig. 1) or selective protection procedures and subsequent acylation with acylchlorides (Fig. 2) for quercetin derivatives preparation. Structures of tested compounds are outlined in Tab. 1.

In view of the above, there have been efforts to produce derivatives of quercetin having improved aqueous solubility or solubility in pharmaceutically acceptable solvents, which also would be more soluble for use. On the other hand quercetin derivatization could lead to the change of its lipo/ hydrophilic properties and thereby variability of particular retention and distribution parameters in biosystems. The synthesis of different quercetin esters, bearing from mono- to tetra- substituted hydroxyl groups, was achieved in simple acylation procedures whereas yields of isomers depend on the stoichiometric ratio of reagents. The conditions under which such acylation reactions with e.g. acyl halogenide are carried out are well known; they can be carried in the presence of a base and in the 
Tab. 1. Structures of investigated quercetin derivatives.<smiles>[R]C1=CC([R])C2=C(C1)OC(C1CCC([R])C([R9])C1)C([R3])C2=O</smiles>

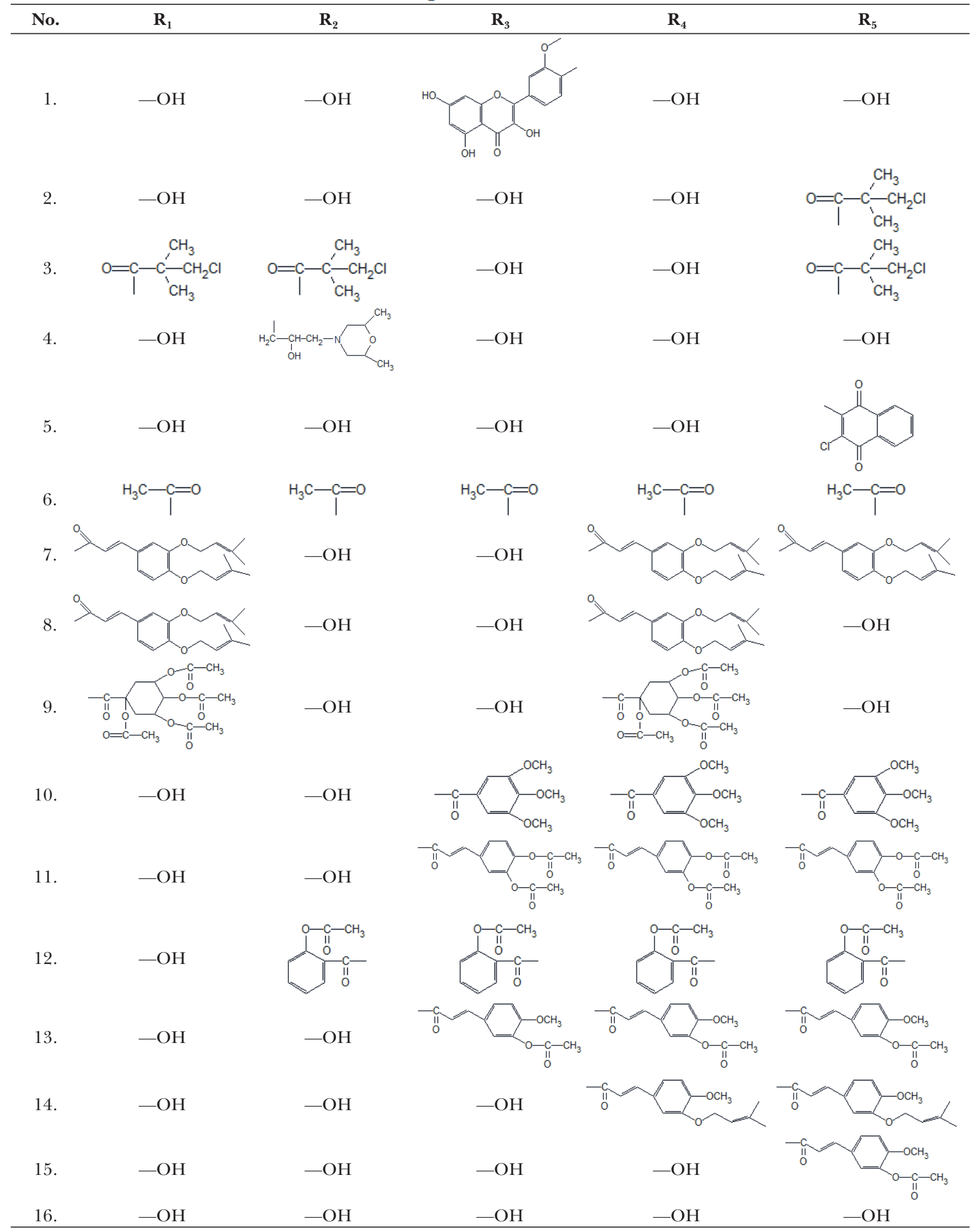


<smiles>O=C1C(O)=C2C(O)C=C(O)C[C@H]2OC1C1=CCC2OC3(C4=CCC(O)C(O)C4)OC4CC(O)C=C(O)C4C(=O)C3(O)OC2=C1</smiles>

Fig. 1. Reaction schema for the preparation of diquercetin (Veverka et al., 2013).

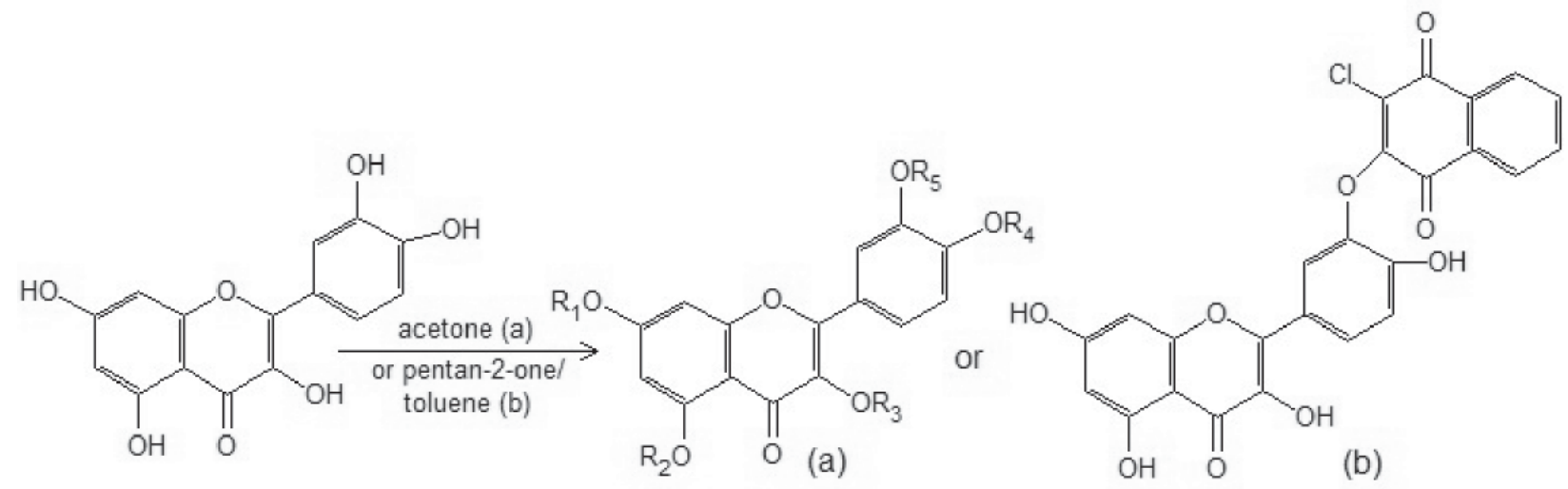

Fig. 2. Reaction schema for the preparation of O-acyl quercetin derivatives (Veverka et al., 2013).

presence of a suitable solvent or alternatively in the presence of an activated carboxylic acid reagent. The acylation reaction can be carried out in conventional manner in the presence of a solvent to allow solubilization of the starting polyphenolic or selectively benzylated (protected) polyphenolic compounds. This acylation can be performed on one or more or even the entire hydroxyl groups of quercetin or benzylated quercetin derivatives. The quercetin skeleton selectively benzylated in various positions may be obtained by known method (Bouktaib et al., 2002). To allow selective derivatization the acetylation/benzylation strategy was adapted (Jurd, 1962). This alkylating method is also used for simple preparation of 3 - or 5- (2,6dimethyl-morpholin-4-yl)-2-hydroxy-1-propyl substituted quercetin.

It is important to selectively modify the hydroxyl groups, which are different from the chemical reactivity point of view. Thus, regioselective O-derivatization of quercetin via ester intermediate (Mattarei et al., 2010) or protection of selective hydroxyl group via benzyl or diphenylmethane group are applied. The synthesis of different quercetin esters, bearing from mono- to tetra- substituted hydroxyl groups, was achieved by simple procedures whereas yields of isomers depend on the stoichiometric ratio of reagents.
The crude reaction mixtures were analyzed (LC-MS) and compared with products isolated by column chromatography. LC-MS spectra were acquired using an Agilent 1100 HPLC-MSD SL Ion Trap mass spectrometer with a multi-mode ion source (ESI, APCI, Agilent Technologies, USA). The purity of all the samples tested as determined by HPLC was approximately $99.8 \%$. In TLC analysis retention factors were estimated. Characteristics of prepared derivatives are listed in Table 2.

\section{Inhibitory effect on serine proteases}

To study inhibitory effects on serine proteases we have choosed digestive proteases trypsin and pancreatic elastase, blood coagulation protease thrombin and fibrinolytic protease urokinase as experimental models. Elevated activities of these enzymes have a role in the development of some diseases (e.g. cancer, inflammation, cardiovascular disorders). Specific inhibition of particular enzymes is desirable in view of the retardation till elimination of mentioned diseases. Found inhibitors become thereby potential therapeutics. Quercetin and its acylated derivatives were subjected to test their antiproteinase action using chromogenic substrates for monitoring of their inhibition effects. 4-guanidinobenzoic acid served as the standard serine protease inhibitor. For each of derivatives there 
Tab. 2. Physicochemical characteristics of quercetin and its new synthesized derivatives.

\begin{tabular}{rlccc}
\hline No. & Name & $\mathbf{M W}^{\mathbf{a}}$ & $\mathbf{M p}^{\mathbf{b}}\left({ }^{\circ} \mathbf{C}\right)$ & $\mathbf{R}_{\mathbf{f}}{ }^{\mathbf{c}}$ \\
\hline 1. & Diquercetin & 602.5 & $205-215$ & $0.30^{*}$ \\
2. & Monochloropivaloyl quercetin & 420.8 & $93-100$ & $0.60^{*}$ \\
3. & Tri(monochloropivaloyl) quercetin & 657.9 & $95-98$ & $0.60^{*}$ \\
4. & 5-Morfolinohydroxypropoxy quercetin & 473.5 & $65-70$ & nd \\
5. & Chloronaphtoquinone quercetin & 492.8 & $165-170$ & $0.50^{*}$ \\
6. & Pentaacetyl quercetin & 512.4 & $190-195$ & $0.80^{* * * *}$ \\
7. & Tri(diprenylcaffeoyl) quercetin & 1196.5 & $49-53$ & $0.79^{* * *}$ \\
8. & Di(diprenylcaffeoyl) quercetin & 899.0 & $48-52$ & $0.21^{* * *}$ \\
9. & Di(tetraacetylquinoyl) quercetin & 986.2 & $107-114$ & $0.28^{* *}$ \\
10. & Tri(trimethylgalloyl) quercetin & 884.4 & $160-161$ & $\mathrm{nd}$ \\
11. & Tri(diacetylcaffeoyl) quercetin & 1040.9 & $118-122$ & $0.85^{*}$ \\
12. & Tetra(acetylsalicyloyl) quercetin & 950.8 & $100-104$ & $0.90^{*}$ \\
13. & Tri(acetylferuloyl) quercetin & 956.9 & $126-133$ & $0.60^{* * * *}$ \\
14. & Di(prenylferuloyl) quercetin & 790.8 & $80-85$ & $0.90^{*}$ \\
15. & Monoacetylferuloyl quercetin & 520.5 & $176-183$ & nd \\
16. & Quercetin & 302.2 & 316 & $0.30^{*}$ \\
\hline
\end{tabular}

${ }^{a}$ Molecular weight (MW).

${ }^{b}$ Melting point (Mp) (uncorrected) were determined on a Boetius Nagema-type hot-stage apparatus (Rapido Wägetechnik, Germany).

${ }^{\mathrm{c}}$ Retention factor $\left(\mathrm{R}_{\mathrm{f}}\right)$ determined by TLC analysis.

nd - not determined.

*TLC conditions: dichloromethane/methanol/formic acid (9/0.5/0.1, v/v/v)

**TLC conditions: dichloromethane/methanol/formic acid $(9 / 0.2 / 0.1, \mathrm{v} / \mathrm{v} / \mathrm{v})$

***TLC conditions: dichloromethane/methanol/formic acid (9/0.1/0.1, v/v/v)

****TLC conditions: ethylacetate/methanol $(9 / 0.1, \mathrm{v} / \mathrm{v})$

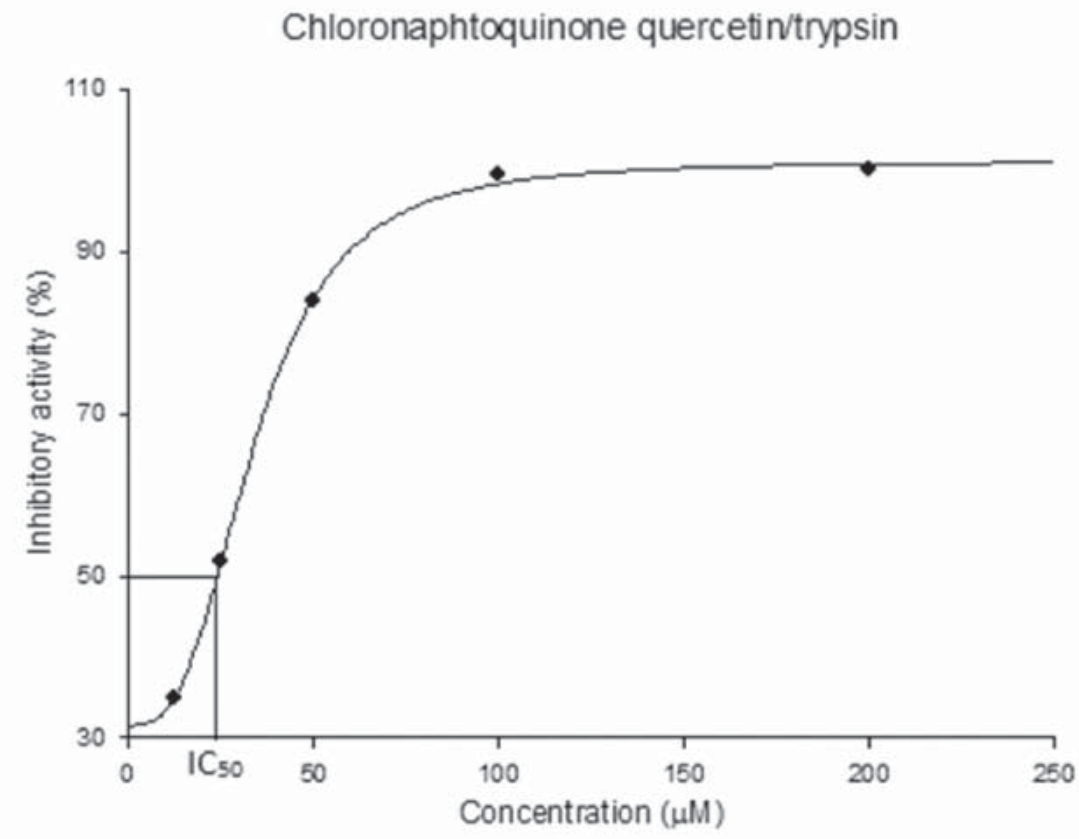

Fig. 3. Demonstration for calculation of $\mathrm{IC}_{50}$ value for chloronaphtoquinone quercetin and trypsin. 
was determined inhibition effect at several used concentrations (Fig. 3). Inhibitory effects expressed in concentrations required to decrease enzyme activity by $50 \%\left(\mathrm{IC}_{50}\right)$ are summarized in Tab. 3 .

Prepared novel quercetin esters and conjugates were the most potent inhibitors of thrombin. All of them effectively inhibited this enzyme at tested concentrations. Quercetin was about ten times better than standard serine protease inhibitor. One half of derivatives displayed better thrombin inhibitory effect in comparison with quercetin (4.1 to $7.1 \mu \mathrm{M})$. This was seen mainly for acetylated, prenylated, caffeoyl and feruloyl quercetin esters. For efficient thrombin cleavage hydrophobic residues in substrate structure are required (Chang, 1985). This finding can explain that more hydrophobic quercetin esters were more effective in this testing.

Trypsin and urokinase were inhibited by quercetin and standard inhibitor at the same level. These results support the fact that human urokinase has $40 \%$ identity to bovine trypsin and the substrate specificities are virtually identical (Steffens et al., 1982). Slight improvement in inhibition of both enzymes have shown diquercetin $(23.3$ and $27.3 \mu \mathrm{M})$ and chloronaphtoquinone quercetin (23.5 and $25.3 \mu \mathrm{M})$. The last one was effective in inhibiting of thrombin, too $(6.1 \mu \mathrm{M})$.

Only slight inhibitory effect on elastase was seen. Standard inhibitor 4-guanidinobenzoic acid did not inhibit this enzyme at tested concentrations. Among screened derivatives diquercetin revealed improved inhibition $(54.0 \mu \mathrm{M})$ as compared to quercetin $(65.2 \mu \mathrm{M})$. Brás et al. (2010) have found a positive relationship between the degree of polyphenol polymerization and the capacity of the polyphenols to inhibit pancreatic elastase. Hydrogen bond interactions and hydrophobic effects established between the polpyhenol groups and the side chain of residues stabilize and favour the binding mode mainly for procyanidin tetramer. This can explain our observation that quercetin dimer has higher affinity to this enzyme than its monomer.

We suggest that increased inhibitory properties of the acylated quercetin derivatives mainly in the case of thrombin inhibiton may be connected with enhanced hydrophobicity of the compounds. Suitable acyl introduced on the quercetin skeleton would provide probably an interaction with hydrophobic region of the enzyme and would thus provide a better inhibitory effect (Fig. 4).

In accordance with this claim Kartasasmita et al. (2010) suggested that quercetin modification by acetylation and halogenation increased the lipophilicity of quercetin and furthermore enhanced its inhibitory effects on nitric oxid synthase. Acylated hesperitin revealed better elastase inhibitory action even at low concentrations than unmodified hesperitin (Boumendjel et al., 2003). We previously

Tab. 3. Inhibitory effects of quercetin and its derivatives on trypsin, thrombin, urokinase and elastase expressed in $\mathrm{IC}_{50}$ values $(\mathrm{n}=5)$.

\begin{tabular}{|c|c|c|c|c|c|}
\hline \multirow{2}{*}{ No. } & \multirow{2}{*}{ Name } & \multicolumn{4}{|c|}{$\mathrm{IC}_{50 \pm} \mathrm{SD}(\mu \mathrm{M})$} \\
\hline & & Trypsin & Thrombin & Urokinase & Elastase \\
\hline 1. & Diquercetin & $23.3 \pm 2.3$ & $10.2 \pm 0.2$ & $27.3 \pm 1.2$ & $54.0 \pm 2.1$ \\
\hline 2. & Monochloropivaloyl quercetin & $>200$ & $24.6 \pm 1.3$ & $>200$ & $65.6 \pm 0.9$ \\
\hline 3. & Tri(monochloropivaloyl) quercetin & $69.4 \pm 2.3$ & $34.0 \pm 0.6$ & $>200$ & $>200$ \\
\hline 4. & 5-Morfolinohydroxypropoxy quercetin & $>200$ & $89.5 \pm 3.3$ & $47.0 \pm 0.8$ & $>200$ \\
\hline 5. & Chloronaphtoquinone quercetin & $23.5 \pm 1.1$ & $6.1 \pm 0.1$ & $25.3 \pm 1.1$ & $>200$ \\
\hline 6. & Pentaacetyl quercetin & $>200$ & $94.5 \pm 2.1$ & $>200$ & $>200$ \\
\hline 7. & Tri(diprenylcaffeoyl) quercetin & $>200$ & $5.2 \pm 0.3$ & $26.8 \pm 0.6$ & $>200$ \\
\hline 8. & Di(diprenylcaffeoyl) quercetin & $>200$ & $6.3 \pm 0.3$ & $82.3 \pm 2.1$ & $135.4 \pm 4.1$ \\
\hline 9. & Di(tetraacetylquinoyl) quercetin & $>200$ & $63.5 \pm 2.3$ & $>200$ & $>200$ \\
\hline 10 & Tri(trimethylgalloyl) quercetin & $>200$ & $18.0 \pm 0.5$ & $>200$ & $>200$ \\
\hline 11. & Tri(diacetylcaffeoyl) quercetin & $23.2 \pm 0.1$ & $4.1 \pm 0.3$ & $>200$ & $>200$ \\
\hline 12. & Tetra(acetylsalicyloyl) quercetin & $65.2 \pm 5.1$ & $70.0 \pm 1.9$ & $42.2 \pm 1.7$ & $>200$ \\
\hline 13. & Tri(acetylferuloyl) quercetin & $26.7 \pm 0.2$ & $4.3 \pm 0.2$ & $25.0 \pm 0.5$ & $>200$ \\
\hline 14. & Di(prenylferuloyl) quercetin & $44.1 \pm 0.3$ & $6.9 \pm 0.4$ & $24.8 \pm 1.6$ & $185.3 \pm 4.4$ \\
\hline 15 & Monoacetylferuloyl quercetin & $47.6 \pm 1.2$ & $7.1 \pm 0.1$ & $>200$ & $>200$ \\
\hline 16. & Quercetin & $26.5 \pm 1.2$ & $7.4 \pm 0.2$ & $27.5 \pm 1.3$ & $65.2 \pm 2.9$ \\
\hline 17. & 4-Quanidinobenzoic acid & $22.5 \pm 0.6$ & $67.7 \pm 3.2$ & $28.7 \pm 0.9$ & $>200$ \\
\hline
\end{tabular}




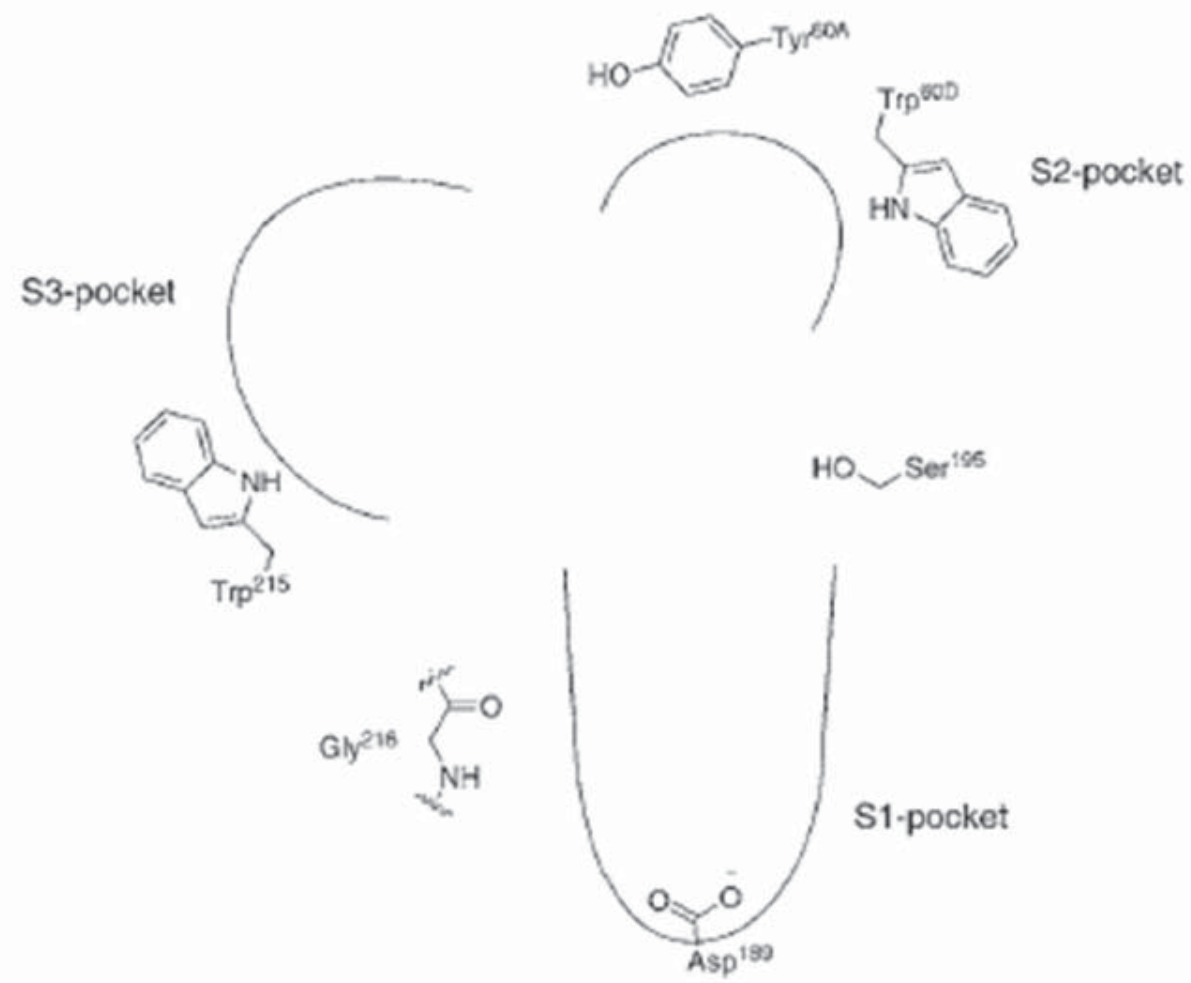

Fig. 4. The scheme of the active site of thrombin that is mostly hydrophobic (Wu et al., 2007).

found that lipophilic polyphenol fatty acid esters improved their inhibitory effect on serine proteases (Viskupičová et al., 2012).

In the previous study we have shown that the highest inhibitory effect on aldose reductase was found for chloronaphtoquinone quercetin being one order higher than quercetin itself (Veverka et al., 2013). This derivative was slightly more effective in inhibiting of trypsin, thrombin and urokinase, too. However, no effect on elastase activity was seen.

\section{Conclusions}

Quercetin is a flavonoid with common occurrence in the nature. It proves many health beneficial properties. We have monitored the ability of novel quercetin esters and conjugates to inhibit the activity of serine proteases. Tested derivatives exhibited the best inhibitory effect on thrombin. Improved inhibition was seen mainly for prenylated, acetylated, caffeoyl, feruloyl quercetin esters and quercetin dimer. Trypsin and urokinase were inhibited at the same level. Slight enhancement of inhibition of both enzymes revealed diquercetin and chloronaphtoquinone quercetin. For all of tested derivatives only slight inhibitory effect on elastase was found. Diquercetin was the most effective in this case. Obtained results indicate that certain modifications of quercetin structure could improve its biological properties mainly because of higher lipophilicity of new compounds. Moreover this attribute may help derivatives to enhance their bioavailability. Tested quercetin derivatives are on the present evaluated for their bioactivities on the cellular level.

\section{Acknowledgement}

This work was supported by courtesy of The Agency of the Ministry of Education, Science, Research and Sport of the Slovak Republic for the Structural Funds of EU in the frame of the Project Evaluation of natural substances and their selection for prevention and treatment of lifestyle diseases (ITMS 26240220040).

\section{References}

Bieth J, Spiess B, Wermuth CG (1974) Biochemical Medicine 11: 350-357.

Boots AW, Haenen GR, Bast A (2008) European Journal of Pharmacology 585: 325-337.

Bouktaib M, Lebrun S, Atmani A, Rolando C (2002) Tetrahedron 58: 10001-10009.

Boumendjel A, Mariotte AM, Bresson-Rival D, Perrier E (2003) Pharmaceutical Biology 41: 546-549.

Brás NF, Gonçalves R, Mateus N, Fernandes PA, Ramos MJ, de Freitas V (2010) Journal of Agricultural and Food Chemistry 58: 10668-10676.

Carriero MV, Franco P, Votta G, Longanessi-Cattani I, Vento MT, Masucci MT, Mancini A, Caputi M, Iaccarino I, Stoppelli MP (2011) Current Drug Targets 12: $1761-1771$.

Chang JY (1985) European Journal of Biochemistry 151: $217-224$. 
Chen YC, Shen SC, Lee WR, Hou WC, Yang LL, Lee TJ (2001) Journal of Cellular Biochemistry 82: 537-548.

Devipriya S, Vani G, Ramamurthy N, Shyamaladevi CS (2006) Chemotherapy 52: 60-65.

Erlanger BF, Kokowsky M, Cohen W (1961) Archives of Biochemistry and Biophysics 95: 271-278.

Jedinák A, Maliar T, Grancai D, Nagy M (2006) Phytotherapy Research 20: 214-217.

Jurd L (1962) The Journal of Organic Chemistry 27: 1294-1297.

Kanashiro A, Souza JG, Kabeya LM, Azzolini AECS, Lucisano-Valim YM (2007) Zeitschrift für Naturforschung 62c: 357-361.

Kartasasmita RE, Herowati R, Gusdinar T (2010) Journal of Applied Sciences 10: 3098-3104.

Keisuke M, Masahiko H, Yu K, Atsushi I, Masaki O, Hiroki S, Michio O (2005) Pancreas 31: 54-62.

Korkmaz B, Horwitz MS, Jenne DE, Gauthier F (2010) Pharmacological Reviews 62: 726-759.

Krenn L, Wollenweber E, Steyrleuthner K, Görick C, Melzig MF (2009) Fitoterapia 80: 267-269.

Kružlicová D, Danihelová M, Veverka M (2012) Nova Biotechnologica et Chimica 11: 37-44.

Liu L, Ma H, Yang N, Tang Y, Guo J, Tao W, Duan J (2010) Thrombosis Research 126: 365-378.

Maliar T, Jedinák A, Kadrabová J, Šturdík E (2004) European Journal of Medicinal Chemistry 39: 241-248.

Mattarei A, Biasutto L, Rastrelli F, Garbisa S, Marotta E, Zoratti M, Paradisi C (2010) Molecules 15: 4722 4736.

Mozzicafreddo M, Cuccioloni M, Eleuteri AM, Fioretti E, Angeletti M (2006) Biochimie 88: 1297-1306.

Muri EMF, Gomes Jr. M, Albuquerque MG, da Cunha EFF, de Alencastro RB, Williamson JS, Antunes OAC (2005) Amino Acids 28: 413-419.
Nieuwenhuizen W, Wijngaards G, Groeneveld E (1977) Thrombosis Research 11: 87-89.

Parellada J, Guinea M (1995) Journal of Natural Products 58: 823-829.

Petros S, Siegemund R (2011) Medizinische Klinik - Intensivmedizin und Notfallmedizin 3: 166-170.

Philips N, Samuel M, Arena R, Chen YJ, Conte J, Natarajan P, Haas G, Gonzalez S (2010) Journal of Cosmetic Science 61: 125-132.

Shahwar D, Raza MA, ur Rahman A (2012) Journal of the Science of Food and Agriculture in press.

Steffens GJ, Günzler WA, Otting F, Frankus E, Flohé L (1982) Hoppe-Seyler's Zeitschrift für Physiologische Chemie 363: 1043-1058.

Takahama U, Koga Y, Hirota S, Yamauchi R (2011) Food Chemistry 126: 1808-1811.

Veverka M, Gallovič J, Švajdlenka E, Veverková E, Prónayová N, Miláčková I, Štefek M (2013) Chemical Papers 67: 76-83.

Vinazzer H (1975) Haemostasis 4: 101-109.

Viskupičová J, Ondrejovič M, Šturdík E (2008) Journal of Food and Nutrition Research 47: 151-162.

Viskupičová J, Danihelová M, Majeková M, Liptaj T, Šturdík E (2012) Journal of Enzyme Inhibition and Medicinal Chemistry 27: 800-809.

Walker B, Lynas JF (2001) Cellular and Molecular Life Sciences 58: 596-624.

Wu EL, Mei Y, Han K, Zhang JZH (2007) Biophysical Journal 92: 4244-4253.

Yamamoto H, Iku S, Adachi Y, Imsumran A, Taniguchi H, Nosho K, Min Y, Horiuchi S, Yoshida M, Itoh F, Imai K (2003) The Journal of Pathology 199: 176-184. 